\title{
Fabrication of Nanostructured Palladium Within Tridentate Schiff-Base-Ligand Coordination Architecture: Enhancement of Electrocatalytic Activity Toward $\mathrm{CO}_{2}$ Electroreduction
}

\author{
Anna Wadas • Iwona A. Rutkowska • Adam Gorczyński • \\ Maciej Kubicki • Violetta Patroniak • Pawel J. Kulesza
}

Published online: 22 May 2014

(C) The Author(s) 2014. This article is published with open access at Springerlink.com

There has been growing interest in the electrochemical reduction of carbon dioxide $\left(\mathrm{CO}_{2}\right)$, a potent greenhouse gas and a contributor to global climate change, and its conversion into useful carbon-based fuels or chemicals [1-5]. Numerous homogeneous and heterogeneous catalytic systems have been proposed to induce the $\mathrm{CO}_{2}$ reduction and, depending on the reaction conditions (applied potential, choice of buffer, its strength and $\mathrm{pH}$, local $\mathrm{CO}_{2}$ concentration, or the catalyst used) various products that include carbon monoxide, oxalate, formate, carboxylic acids, formaldehyde, acetone, or methanol, as well as such hydrocarbons as methane, ethane, and ethylene, are typically observed at different ratios. These reaction products are of potential importance to energy technology, food research, medical applications, and fabrication of plastic materials.

Given the fact that the $\mathrm{CO}_{2}$ molecule is very stable, its electroreduction processes are characterized by large overpotentials, and they are not energy efficient. To produce highly efficient and selective electrocatalysts, the transitionmetal-based molecular materials are often considered [6-8]. The latter systems are capable of driving multi-electron transfers and, in principle, produce highly reduced species. In reality, such multi-electron charge transfer catalysts tend to effectively induce the two-electron reduction of $\mathrm{CO}_{2}$ to $\mathrm{CO}$ rather than yield highly reduced products in large amounts. Metallic copper electrodes are unique in this respect because they can drive multi-electron transfers. Mechanisms of the

\footnotetext{
A. Wadas I. A. Rutkowska P. J. Kulesza $(\square)$

Faculty of Chemistry, University of Warsaw, Pasteura 1, 02093 Warsaw, Poland

e-mail: pkulesza@chem.uw.edu.pl

A. Gorczyński • M. Kubicki • V. Patroniak $(\bowtie)$

Faculty of Chemistry, Adam Mickiewicz University,

Umultowska 89b, 61614 Poznan, Poland

e-mail: violapat@amu.edu.pl
}

successful electrochemical reductions of $\mathrm{CO}_{2}$ to methane and ethylene can be interpreted in terms of complex processes occurring at copper electrodes $[9,10]$. It is believed that, during electroreduction, the rate limiting step is the protonation of the adsorbed $\mathrm{CO}$ product to form the $\mathrm{CHO}$ adsorbate [11]. Significant decrease of the reaction overpotentials can be achieved with the use of the metal complex modified electrodes capable of both mediating electron transfers and stabilizing the reduced products [12].

Because reduction of $\mathrm{CO}_{2}$ can effectively occur by hydrogenation [13], in the present work, we concentrate on such a model catalytic system as nanostructured metallic palladium capable of absorbing reactive hydrogen in addition to the ability to adsorb monoatomic hydrogen at the interface [14-16]. Under such conditions, the two-electron reduction of $\mathrm{CO}_{2}$ typically to $\mathrm{CO}$ [12] is favored. When the reaction proceeds on palladium in aqueous $\mathrm{KHCO}_{3}$ solutions, carbon monoxide together with hydrogen and small amounts of formate are produced [17-19]. Further, it has been postulated that $\mathrm{CO}$ and $\mathrm{COOH}$ adsorbates are expected to be formed at the surfaces of $\mathrm{Pd}$ electrodes at $-1.0 \mathrm{~V}$ (vs. $\mathrm{Ag} / \mathrm{AgCl}$ ) and, subsequently, desorbed at even more negative potentials [20].

To produce highly dispersed and stabilized palladium nanoparticles (as for Fig. 1a), we have generated them by electrodeposition (through consecutive potential cycling) from the thin film of $\mathrm{N}$-coordination complex of palladium(II), $\left[\mathrm{Pd}\left(\mathrm{C}_{14} \mathrm{H}_{12} \mathrm{~N}_{2} \mathrm{O}_{3}\right) \mathrm{Cl}_{2}\right]_{2} \mathrm{MeOH}$. The ligand and its palladium complex (their detailed crystallographic, IR, and NMR features will be a subject of our next publication) were synthesized via typical condensation reaction as published earlier [21, 22]. The resulting metallic Pd nanoparticles (diameters, 5-10 nm), rather than Pd cationic species, are stabilized and activated by nitrogen coordination centers from the macromolecular matrix. Supramolecular architectures of active and well-defined Schiff-base-ligands containing nitrogen donor atoms are of primary importance because 
of the capability of these "privileged ligands" to stabilize different metals in various oxidation states. Historically, macromolecular complexes of certain transition metals were demonstrated to exhibit appreciable activity toward electroreduction of carbon dioxide. Representative examples include complexes of iron, cobalt, and nickel with terdentate ligands [23], mono(bipyridine)carbonylruthenium complexes (investigated both in solution or as polymeric thin films) [24], rhodium complexes containing 2,4,6-Tris(2-pyridyl)-1,3,5-triazine [25], bimetallic palladium complexes [26], or iron(0) porphyrins $[27,28]$. In addition to the catalytic activity of a metallic site, the activating role of a ligand should also be appreciated. Recently, a homogeneous catalytic system utilizing pyridinium cation which has been found to drive the sixelectron reduction of $\mathrm{CO}_{2}$ to methanol $[29,30]$ should be mentioned. In the present work, we have found that stabilization and activation of highly dispersed nanostructured metallic $\mathrm{Pd}$ centers with a tridentate Schiff-base-ligand is feasible and results in the electrocatalytic enhancement of the $\mathrm{CO}_{2}$ reduction.

To generate Pd nanocenters supported within the macromolecular network of tridentate Schiff-base-ligands, the following steps were undertaken. First, to prepare a suspension of $\mathrm{N}$-coordinated palladium(II) complex, $\left[\mathrm{Pd}\left(\mathrm{C}_{14} \mathrm{H}_{12} \mathrm{~N}_{2} \mathrm{O}_{3}\right) \mathrm{Cl}_{2}\right]_{2} \mathrm{MeOH}[21,22]$, a known amount $(1.9 \mathrm{mg})$ of it was dispersed in $1.9 \mathrm{ml}$ of acetonitrile. Second, $2 \mu$ of the suspension was dropped onto the surface of a glassy carbon electrode (geometric area, $0.071 \mathrm{~cm}^{2}$ ) by a micropipette to form a film which was subsequently dried and stabilized by depositing $1 \mu \mathrm{l}$ of the Nafion solution (prepared by dissolving the commercial $5 \%$ of Nafion perfluorinated resin solution in ethanol at the 1 to 10 volumetric ratio). Later, the resulting modified electrode was subjected to the voltammetric cycling ( 25 full cycles at $50 \mathrm{mV} \mathrm{s}^{-1}$ ) in the potential range from 1.10 to $-0.68 \mathrm{~V}$ in deaerated $0.1 \mathrm{~mol} \mathrm{dm}^{-3}$ of $\mathrm{KHCO}_{3}$ (Fig. 2a). Electrochemical measurements were performed with the use of $\mathrm{CH}$ Instruments $760 \mathrm{E}$ workstation in a three-electrode configuration at $22{ }^{\circ} \mathrm{C}$. The reference electrode was a mercury/mercury sulfate electrode $\left(\mathrm{Hg} / \mathrm{Hg}_{2} \mathrm{SO}_{4}\right)$, but all potentials were reported here versus the reversible hydrogen electrode (RHE). The gold rod was used as an inert counter electrode. Under repetitive potential cycling conditions (Fig. 2a), the N-coordinated Pd(II) sites were slowly electroreduced to produce metallic $\operatorname{Pd}(0)$ centers stabilized with well-defined Schiff-base-ligands containing nitrogen donor atoms. The appearance of growing hydrogen evolution and hydrogen sorption currents during consecutive potential cycling shown in Fig. 2a is consistent with the formation of the catalytic metallic $\operatorname{Pd}(0)$ centers. Application of 25 full potential cycles is enough to generate Pd catalytic sites; their electrochemical characteristics (Fig. 2b) and morphology (Fig. 1) will be discussed below.
Figure 1a illustrates a transmission electron micrograph (TEM) of the electrogenerated palladium nanostructures: their sizes (diameters) are typically on the level a few nanometers (some of them tend to agglomerate to form nanoparticles ranging in diameters from 5 to $10 \mathrm{~nm}$ ). Here, TEM images were obtained with JEM 1400 (JEOL, Japan). From the amount of the complex deposited on electrode, the loading of palladium has been estimated to be on the level of $100 \mu \mathrm{g} \mathrm{cm}^{-2}$. For comparison, we also considered commercially available Pd nanoparticles (from Sigma Aldrich); it is apparent from their TEM image (Fig. 1b) that sizes of the nanoparticles are somewhat larger (diameters from 10 to $20 \mathrm{~nm}$ ).

Curve a in Fig. 2b illustrates a cyclic voltammetric response of the tridentate Shift-base-ligand stabilized nanostructured palladium (film on glassy carbon) recorded in the deaerated (by purging argon for $20 \mathrm{~min}$ ) $0.1 \mathrm{~mol} \mathrm{dm}^{-3}$ of $\mathrm{KHCO}_{3}(\mathrm{pH}=8.8)$. To perform comparative electrochemical measurements, the conventional Pd black catalyst was deposited on glassy carbon at the same loading $\left(100 \mu \mathrm{g} \mathrm{cm}^{-2}\right)$. To prepare ink, commercial Pd nanoparticles $(0.071 \mathrm{~g})$ were dispersed in aqueous suspension $(2 \mathrm{ml})$ and subjected to

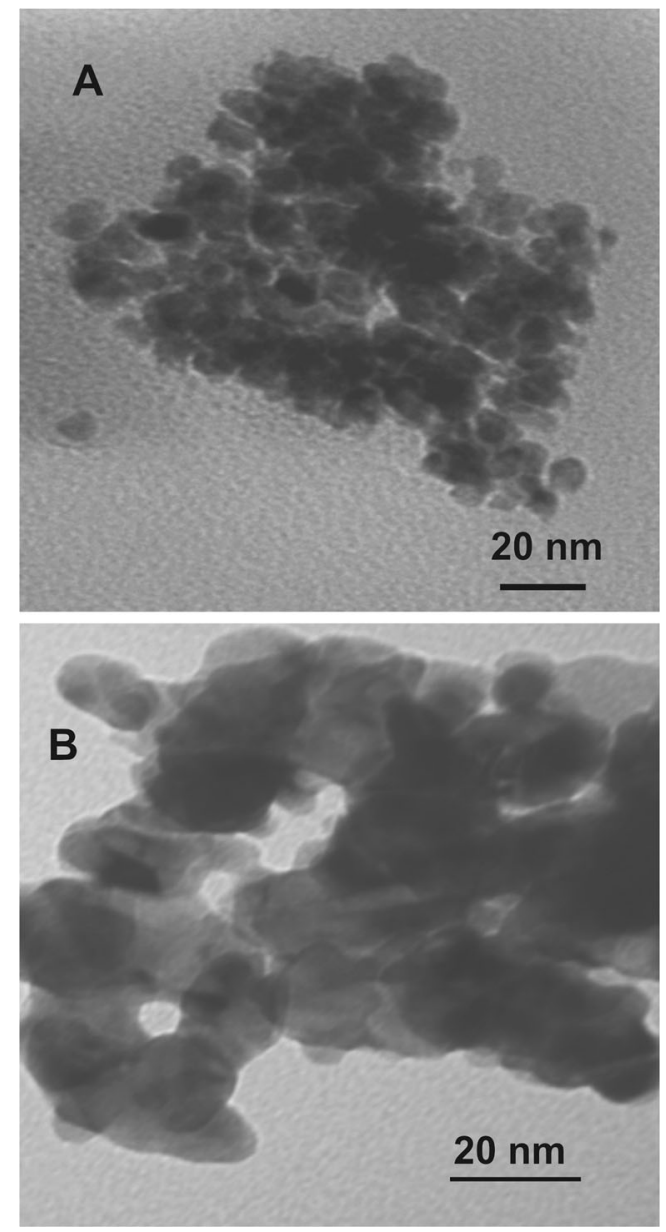

Fig. 1 Transmission electron micrographs of a tridentate-Schiff-baseligand supported Pd nanostructures and $\mathbf{b}$ conventional Pd nanoparticles 


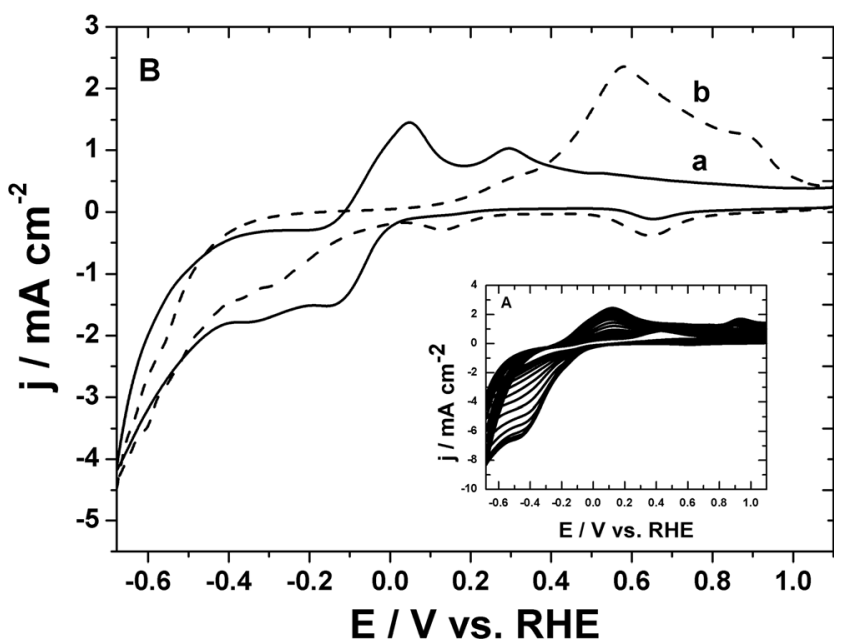

Fig. 2 a Electrodeposition of metallic $\mathrm{Pd}$ sites by subjecting the Ncoordination complex of palladium(II), $\left[\mathrm{Pd}\left(\mathrm{C}_{14} \mathrm{H}_{12} \mathrm{~N}_{2} \mathrm{O}_{3}\right) \mathrm{Cl}_{2}\right]_{2} \mathrm{MeOH}$, to repetitive voltammetric cycling (25 full potential cycles at $50 \mathrm{mV} \mathrm{s}^{-1}$ ) in the range from 1.10 to $-0.68 \mathrm{~V}$ in deaerated $0.1 \mathrm{~mol} \mathrm{dm}^{-3} \mathrm{KHCO}_{3}$. b Cyclic voltammetric responses of (curve a) tridentate-Schiff-base-ligand supported Pd nanostructures and (curve b) conventional Pd nanoparticles (on glassy carbon) recorded at the $10 \mathrm{mV} \mathrm{s}^{-1}$ scan rate in $0.1 \mathrm{~mol} \mathrm{dm}^{-3}$ of $\mathrm{KHCO}_{3}$ under the atmosphere of argon

sonication for $2 \mathrm{~h}$. Later, a $2-\mu \mathrm{l}$ sample of this ink was introduced using a micropipette onto the glassy carbon electrode surface. For comparison, curve b in Fig. $2 b$ provides a cyclic voltammogram characteristic of the conventional $\mathrm{Pd}$ nanoparticles. Both systems (curves a and b in Fig. 2b) yield hydrogen evolution currents at potentials lower than $-0.4 \mathrm{~V}$. At more positive potentials, hydrogen sorption/desorption peaks appear: they are better defined and more reversible in a case of palladium assembled within coordination architecture (Fig. 2b, curve a). The drawn out shape of the hydrogen sorption/desorption voltammetric peaks (Fig. 2b, curve b) implies fairly strong interactions of the electrolyte carbonate anions with conventional palladium nanostructures. Apparently, stabilization of Pd nanocenters within the network of N-donor ligands (as for curve a in Fig. 2b) minimizes the blocking interactions with carbonates and favors reversible sorption of hydrogen. The fact that the voltammetric pattern of curve a in Fig. $2 b$ has yielded two separate hydrogen oxidation peaks, this may imply the existence of two different forms of Pd stabilized with Shiff-baseligands and exposed to the carbonate electrolyte.

To get better insight into the hydrogen sorption phenomena, additional voltammetric experiments were performed by exposing the samples described above (as for Fig. 2b) to $0.5 \mathrm{~mol} \mathrm{dm}^{-3}$ of $\mathrm{H}_{2} \mathrm{SO}_{4}$ electrolyte (Fig. 3). It is apparent upon comparison of the voltammetric behaviors of palladium stabilized with N-donor ligands (Fig. 3a) and conventional (ligand-free) palladium nanoparticles (Fig. 3b) that hydrogen sorption currents were of the same order of magnitude as surface oxidation currents. The existence of hydrogen
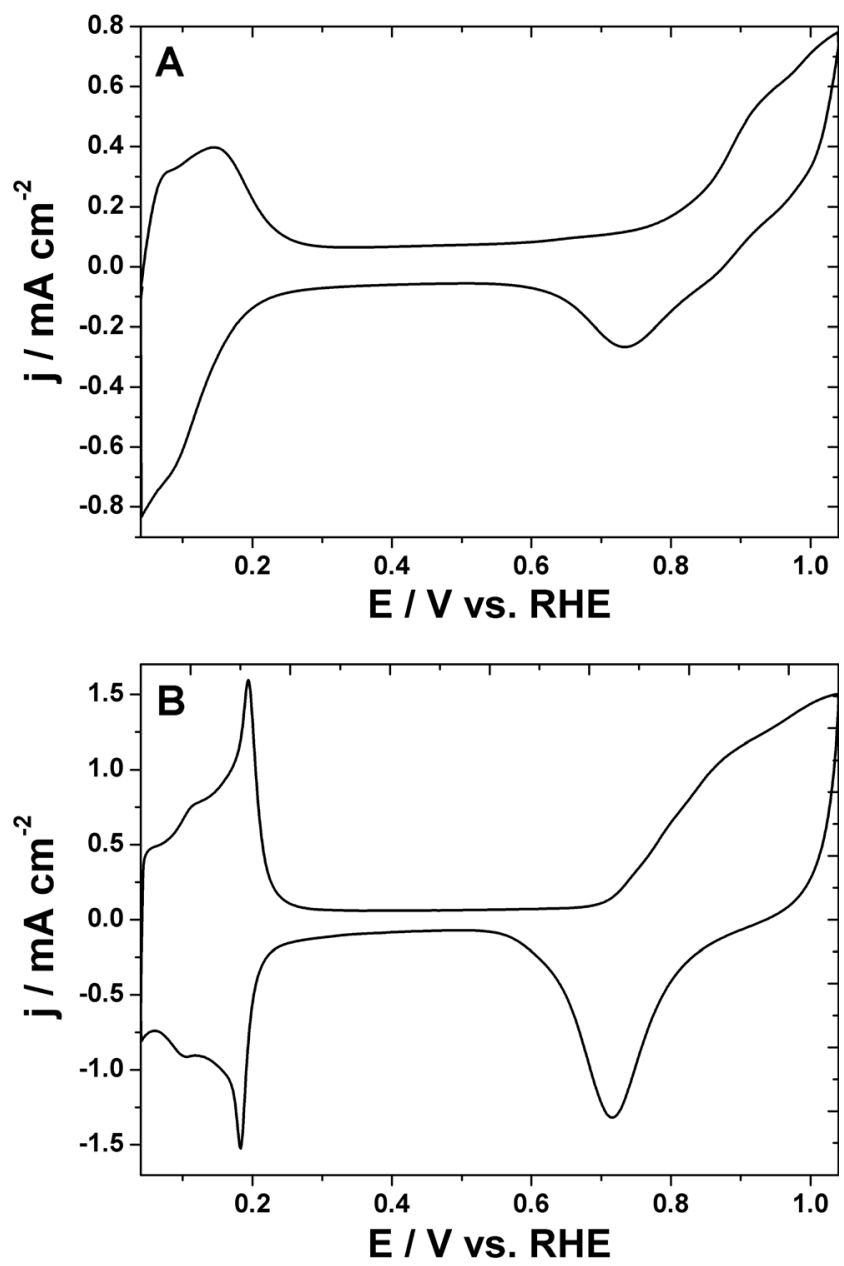

Fig. 3 Cyclic voltammetric responses of a tridentate-Schiff-base-ligand supported Pd nanostructures and $\mathbf{b}$ conventional Pd nanoparticles (on glassy carbon) recorded at the $10 \mathrm{mV} \mathrm{s}^{-1}$ scan rate in $0.5 \mathrm{~mol} \mathrm{dm}^{-3}$ of $\mathrm{H}_{2} \mathrm{SO}_{4}$ under the atmosphere of argon

absorption peaks (in addition to the adsorption ones) was evident in a case of the Pd system existing within the coordination network (Fig. 3a). It has been postulated that hydrogen atoms exhibit high activity toward reduction of $\mathrm{CO}_{2}$ just before absorption into Pd structures [4]. At this stage, it is unclear how the coordination network of the electron-pairdonor nitrogen atoms affects hydrogen sorption phenomena on palladium. Further research (also involving XPS measurements) is planned along this line.

It is also apparent from the data of Fig. $3 b$ that, as expected from literature data [16], electrooxidation of conventional palladium nanoparticles started at about $0.7 \mathrm{~V}$, but the onset potential for electrooxidation of Pd centers stabilized by Schiff-base-ligands was shifted toward more positive values $(0.78 \mathrm{~V})$. This positive shift may reflect the stabilizing effect originating from presence of the network of ligands with nitrogens capable of donating electron pairs.

To diagnose the system's electrocatalytic activity toward reduction of carbon dioxide, the respective voltammetric 
experiments were carried out in $0.1 \mathrm{~mol} \mathrm{dm}^{-3}$ of $\mathrm{KHCO}_{3}$ saturated with $\mathrm{CO}_{2}$ (concentration, $3.42 \times 10^{-2} \mathrm{~mol} \mathrm{dm}^{-3}$ [31]; $\mathrm{pH}=6.8$ ). Despite the approximately same loading of palladium, the system utilizing Pd nanocenters supported within the Schiff-base-ligand coordination architecture (Fig. 4, curve a) exhibited more than three times larger $\mathrm{CO}_{2}$ reduction currents in comparison to those characteristic of conventional Pd nanoparticles (Fig. 4, curve b). Obviously, the electroreduction of $\mathrm{CO}_{2}$ proceeds at potentials lower than $0.1 \mathrm{~V}$, i.e., where hydrogen sorption is operative (compare Figs. $2 \mathrm{~b}$ and 4 ). Apparently, the ability of the coordinatively stabilized Pd nanoparticles to adsorb/absorb reversibly hydrogen is of importance to effective hydrogenation (reduction) of $\mathrm{CO}_{2}$. The appearance of small peaks at potentials more positive than $0.5 \mathrm{~V}$ (Fig. 4) reflects the overlapping phenomena: oxidation of hydrogen and oxidation of the $\mathrm{CO}_{2}$ reduction products, most likely, carbon monoxide and, possibly, formate or formic acid. It is noteworthy that the $\mathrm{CO}_{2}$ reduction voltammograms (Fig. 4), particularly those obtained on conventional Pd nanoparticles (curve b), have analogous shapes to those reported earlier [20].

To get more information about the chemical nature of products of the electroreduction of $\mathrm{CO}_{2}$ at the tridentate Schiff-base-ligand supported palladium, a diagnostic COstripping voltammogram was first recorded in $0.1 \mathrm{~mol} \mathrm{dm}^{-3}$ of $\mathrm{KHCO}_{3}$ electrolyte (Fig. 5, curve 1). Before the measurement, the electrolyte was deoxygenated by purging argon for 20 min and, subsequently, saturated with CO gas simply through bubbling $\mathrm{CO}$ for $10 \mathrm{~min}$. The $\mathrm{CO}$ electrosorption step was achieved by immersing the electrocatalytic electrode (namely modified with the ligand-stabilized-Pd) in the COsaturated solution and by application of $0.3 \mathrm{~V}$ for $5 \mathrm{~min}$. Later,

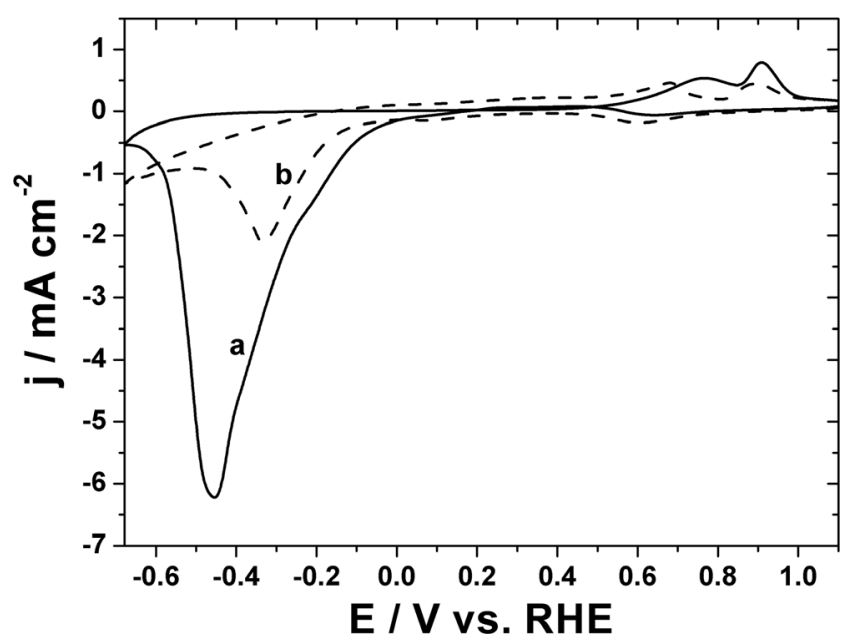

Fig. 4 Voltammetric reduction (at $10 \mathrm{mV} \mathrm{s}^{-1}$ scan rate) of carbon dioxide recorded in the deoxygenated $\mathrm{CO}_{2}$-saturated $0.1 \mathrm{~mol} \mathrm{dm}{ }^{-3}$ of $\mathrm{KHCO}_{3}$ using the following catalytic materials: a tridentate-Schiff-base-ligand supported Pd nanostructures and $\mathbf{b}$ conventional Pd nanoparticles (deposited on glassy carbon). Current densities are provided against the electrode geometric area the dissolved $\mathrm{CO}$ was removed from the solution through purging argon for $20 \mathrm{~min}$ under open-circuit conditions. Then the stripping cyclic voltammogram was recorded in the potential range from 0.0 to $1.1 \mathrm{~V}$ (Fig. 5, curve 1). The appearance of the broad voltammetric peak at potentials starting from ca. $0.75 \mathrm{~V}$ was consistent with the stripping oxidation of $\mathrm{CO}$. The fact that the peak tended to split may reflect the existence of distinct palladium nanostructures at the interface characterized by different $\mathrm{CO}$ oxidation potentials. In another voltammetric measurement performed (at the electrode modified with Pd stabilized with the tridentate-Schiffbase-ligand) in the presence of carbon dioxide, (Fig. 5, curve 2 ), the potential was stepped from $0.3 \mathrm{~V}$ to a preset value of $-0.5 \mathrm{~V}$ and held for a prescribed time of $10 \mathrm{~s}$ during which the products of $\mathrm{CO}_{2}$ electroreduction were formed and adsorbed on the electrode surface. The potential was subsequently stepped to $0.4 \mathrm{~V}$ and scanned (at $10 \mathrm{mV} \mathrm{s}^{-1}$ ) toward more positive values (up to $1.1 \mathrm{~V}$ ). By comparison to the data of Fig. 5 (curve 1), it is reasonable to expect that the most positive peak at about $0.95 \mathrm{~V}$ (curve 2) reflects stripping oxidation of $\mathrm{CO}$ (as the main reaction product as postulated earlier for the Pd-based catalytic system [20]), but the presence of $\mathrm{CO}$ adsorbed on the Pd surface may cause blocking of hydrogen desorption and results in a shift of the peak for hydrogen oxidation toward more positive values; consequently, the absorbed hydrogen oxidation currents are likely to overlap the currents characteristic of the interfacial $\mathrm{CO}$ oxidation [32-34]. A similar effect was observed following adsorption of thiourea on the Pd electrode surface [35, 36]. The exact origin of the peak appearing at less positive potentials, namely starting at ca. $0.35 \mathrm{~V}$ (curve 2) is not certain as yet but - on the basis of our experience with the oxidation of formic acid at Pd

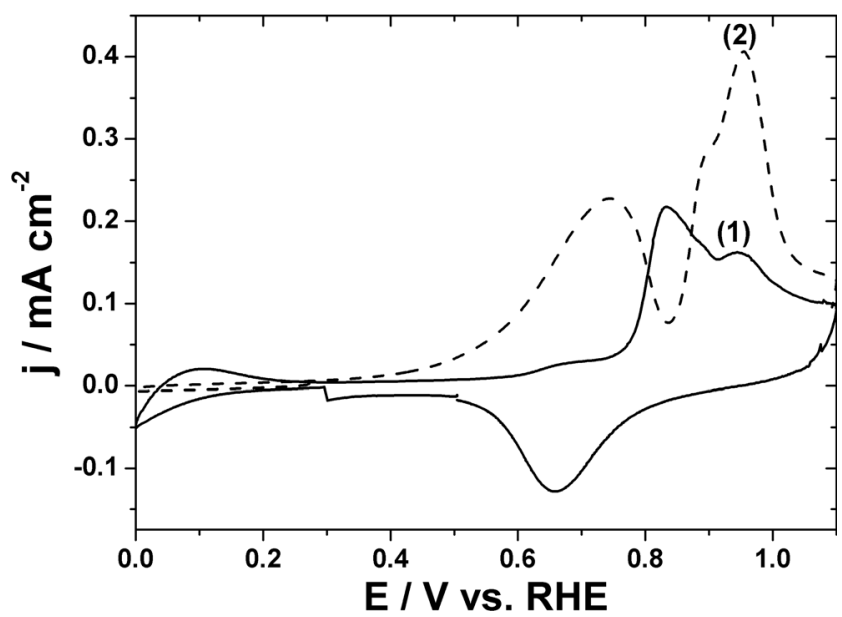

Fig. 5 Voltammetric responses recorded at $10 \mathrm{mV} \mathrm{s}^{-1}$ in $0.1 \mathrm{~mol} \mathrm{dm}^{-3}$ of $\mathrm{KHCO}_{3}$ for curve 1 the stripping of electrosorbed carbon monoxide and curve 2 the oxidative stripping of the $\mathrm{CO}_{2}$ reduction products electrogenerated and sorbed at the tridentate-Schiff-base-ligand supported $\mathrm{Pd}$ nanostructured catalyst. The $\mathrm{CO}_{2}$ reduction products were electrosorbed upon application of $-0.5 \mathrm{~V}$ for $10 \mathrm{~s}$ in the $\mathrm{CO}_{2}$-saturated $0.1 \mathrm{~mol} \mathrm{dm}^{-3}$ of $\mathrm{KHCO}_{3}$ 
$[37,38]$ proceeding at less positive potentials than oxidation of $\mathrm{CO}$ - it is reasonable to attribute it to oxidation of the formate-type species (that could appear as the $\mathrm{CO}_{2}$ reduction by-product). It should be noted that the oxidation currents appearing in the 0.35-0.75 V potential range (Fig. 5, curve 2) were largely absent during experiments performed as above but with conventional Pd nanoparticles. Apparently, formation of other products than $\mathrm{CO}$ was less pronounced in the latter case.

In conclusion, immobilization of nanostructured metallic palladium centers within the supramolecular architecture of Schiff-base-ligands produces a potent catalytic material capable of enhancing the $\mathrm{CO}_{2}$ reduction currents. The electrocatalytic effect cannot be explained simply in terms of larger dispersion and nanostructuring of palladium particles. By using the relationship concerning equivalency of the charge equal to $405 \mu \mathrm{C} \mathrm{cm}^{-2}$ to the reduction of $\mathrm{PdO}$ monolayer under voltammetric conditions in acid medium [39], we can estimate from the data of Fig. 3 the electrochemically active surface areas characteristic of both catalytic systems: palladium stabilized with $\mathrm{N}$-donor ligands (Fig. $3 \mathrm{a}$ ) and conventional (ligand-free) palladium nanoparticles (Fig. 3b). They are equal to 2.5 and $1.5 \mathrm{~cm}^{2}$, respectively. Thus, instead of expressing the voltammetric peak currents of Fig. 4 (curves a and b) against the electrode geometric surface area $\left(0.071 \mathrm{~cm}^{2}\right)$, we can provide now electrocatalytic currents normalized versus the electrochemically active surface areas of both Pd-based electrocatalysts. The obtained values are as follows, 34.7 and $18.7 \mathrm{~mA} \mathrm{~cm}^{-2}$, for the voltammetric reduction of $\mathrm{CO}_{2}$ at the ligand-stabilized Pd nanostructures (Fig. 4, curve a) and at the conventional Pd nanoparticles (Fig. 4, curve b). This result supports our view about the superior electrocatalytic activity of $\operatorname{Pd}(0)$ nanocenters existing within the supramolecular architecture of Schiff-base-ligands, relative to the conventional Pd nanoparticles of the same loading.

We have no evidence for the electrocatalytic activity of the ligand itself under present experimental conditions. Relative to the behavior of conventional Pd nanoparticles, the Schiffbase-ligand supported palladium system exhibits somewhat different hydrogen sorption characteristics that may translate to larger population of reactive hydrogen at the electrocatalytic interface. This situation may favor electroreduction of $\mathrm{CO}_{2}$ through the hydrogenation-like mechanism. Consequently, the hydrogen-containing products, like formate or formic acid, could be produced in addition to carbon monoxide. The existence of specific interactions between electron pairs from nitrogen coordination sites and metallic Pd centers cannot be excluded either. Further research is in progress.

Acknowledgments The support of the National Science Center (NCN), Poland, under the project 2011/03/B/ST4/02409 is gratefully acknowledged.
Open Access This article is distributed under the terms of the Creative Commons Attribution License which permits any use, distribution, and reproduction in any medium, provided the original author(s) and the source are credited.

\section{References}

1. D.L. Dubois, in Encyclopedia of electrochemistry, ed. by A.J. Bard, M. Stratmann (Wiley-VCH Verlag GmbH \& Co. KGaA, Weinheim, 2006), p. 202

2. J.K.W. Frese, in Electrochemical and electrocatalytic reactions of carbon dioxide, ed. by B.P. Sullivan, K. Krist, H.E. Guard (Elsevier, Amsterdam, 1993), p. 145

3. M.M. Halmann, M. Steinberg, in Greenhouse gas carbon dioxide mitigation: Science and technology, ed. by M.M. Halmann, M. Steinberg (Lewis Publishers, Boca Raton, 1999), p. 411

4. Y. Hori, in Modern aspects of electrochemistry, ed. by C.G. Vayenas, R.E. White, M.E. Gamboa-Aldeco, vol. 42 (Springer, New York, 2008), p. 89

5. I. Taniguchi, in Modern aspects of electrochemistry, ed. by J.M. Bockris, B.E. Conway, R.E. White, vol. 20 (Springer, New York, 1989), p. 327

6. Z.-Y. Bian, K. Sumi, M. Furue, S. Sato, K. Koike, O. Ishitani, Inorg. Chem. 47, 10801 (2008)

7. K. Tanaka, D. Ooyama, Coord. Chem. Rev. 226, 211 (2002)

8. K. Toyohara, H. Nagao, T. Mizukawa, K. Tanaka, Inorg. Chem. 34, $5399(1995)$

9. Y. Hori, A. Murata, R. Takahashi, J. Chem. Soc. Faraday Trans. 85, 2309 (1989)

10. N. Hoshi, E. Sato, Y. Hori, J. Electroanal. Chem. 540, 105 (2003)

11. A.A. Peterson, F. Abild-Pedersen, F. Studt, J. Prossmeisl, J.K. Nørskov, Energy Environ. Sci. 3, 1311 (2010)

12. C. Finn, S. Schnittger, L.J. Yellowlees, J.B. Love, Chem. Commun. 48, $1392(2012)$

13. C.J. Stalder, S. Chao, D.P. Summers, M.S. Wrinhton, J. Am. Chem. Soc. 105, 6318 (1983)

14. L.H. Dall'Antonina, G. Tremiliosi-Filho, G. Jerkiewicz, J. Electroanal. Chem. 502, 72 (2001)

15. L.A. Kibler, A.M. El-Aziz, R. Hoyer, D.M. Kolb, Angew. Chem. Int. Ed. 44, 2080 (2005)

16. M. Grden, M. Lukaszewski, G. Jerkiewicz, A. Czerwinski, Electrochim. Acta 53, 7585 (2008)

17. R.P.S. Chaplin, A.A. Wragg, J. App. Electrochem. 33, 1118 (2003)

18. M. Azuma, K. Hashimoto, M. Watanabe, T. Sakata, J. Electroanal. Chem. 294, 299 (1990)

19. M. Azuma, K. Hashimoto, M. Hiramoto, M. Watanabe, T. Sakata, J. Electrochem. Soc. 137, 1773 (1990)

20. D. Kolbe, W. Vielstich, Electrochim. Acta 41, 2457 (1996)

21. A.R. Stefankiewicz, M. Wałęsa-Chorab, H.B. Szcześniak, V. Patroniak, M. Kubicki, Z. Hnatejko, J. Harrowfield, Polyhedron 29, $178(2010)$

22. V. Patroniak, A.R. Stefankiewicz, J.-M. Lehn, M. Kubicki, M. Hoffmann, Eur. J. Inorg. Chem. 1, 144 (2006)

23. C. Arana, S. Yan, M. Keshavarz-K, K.T. Potts, H.D. Abruna, Inorg. Chem. 31, 3680 (1992)

24. M.-N. Collomb-Dunand-Sauther, A. Deronzier, R. Ziessel, Inorg. Chem. 33, 2961 (1994)

25. P. Paul, B. Tyagi, A.K. Bilakhiya, M.M. Bhadbhade, E. Suresh, G. Ramachandraiah, Inorg. Chem. 37, 5733 (1998)

26. J.W. Raebiger, J.W. Turner, B.C. Noll, C.J. Curtis, A. Miedaner, B. Cox, D.L. DuBois, Organometallics 25, 3345 (2006)

27. I. Bhugun, D. Lexa, J.-M. Saveant, J. Am. Chem. Soc. 116, 5015 (1994) 
28. I. Bhugun, D. Lexa, J.-M. Saveant, J. Am. Chem. Soc. 118, 1769 (1996)

29. E.B. Cole, P.S. Lakkaraju, D.M. Rampulla, A.J. Morris, E. Abelev, A.B. Bocarsly, J. Am. Chem. Soc. 132, 11539 (2010)

30. A.J. Morris, R.T. McGibbon, A.B. Bocarsly, Chem. Sus. Chem. 4, 191 (2011)

31. N. Gupta, M. Gattrell, B. MacDougall, J. Appl. Electrochem. 36, 161 (2006)

32. A. Czerwinski, S. Zamponi, R. Marassi, J. Electroanal. Chem. 304, $233(1991)$

33. A. Czerwinski, J. Electroanal. Chem. 379, 487 (1994)
34. G. Maruszczak, A. Czerwinski, Anal. Lett. 28, 2547 (1995)

35. B.E. Conway, J.H. Barber, L. Gao, S.Y. Qian, J. Alloys Compd. 253, 475 (1997)

36. J.N. Han, S.I. Pyun, T.H. Yang, J. Electrochem. Soc. 144, 4266 (1997)

37. I.A. Rutkowska, D. Marks, C. Perruchot, M. Jouini, P.J. Kulesza, Colloids Surf. A Physicochem. Eng. Asp. 439, 200 (2013)

38. Z. Cui, P.J. Kulesza, C.M. Li, W. Xing, S.P. Jiang, Int. J. Hydrogen Energy 36, 8508 (2011)

39. T. Chierchie, C. Mayer, W.J. Lorenz, J. Electroanal. Chem. 135, 211 (1982) 